3. That it shall be of such a shape and figure, that when introduced in the middle of the temporal margin of the cornen, and carried across the anterior chamber, it shall readily puncture the nasal side of that membrane; and when placed in this situation, the cutting edge shall be so far beyond the pupillary margin of the iris, and opposed to so large a portion of its anterior surface, as will prevent its escape beneath the edge of the knife to endanger its division in making the section of the cornea.

4. That when the section of the cornea is thus about to be made, the edge of the knife shall be opposed only to the margin of the section on either side, and not to an extensive portion of its internal surface, whereby its division would be attended with difficulty, as is the case in using Beer's knife."

Mr. Scott's book bears evidence of being written in honesty, and, as far as it goes, forms a striking contrast to the unworthy sixpenny pamphlets which have of late years adorned the history of medical literature, and especially in ophthalmic surgery. In speaking of the propriety of operating on both eyes at the same time, when double cataract exists, our author is opposed to such a proceeding; and with a short extract, which is pregnant with meaning, we shall conclude these observations.

"I am fully aware that if one eye be lost in consequence of the operation, the second eye will rarely be confided to the same operator, and another surgeon will thus have the opportunity of acquiring considerable credit at the expense of his neighbour; but this consideration does not invalidate the arguments that have been used in favor of the single operation, in regard to the welfare of the patient, in comparison with which the advantage of the surgeon deserves not a moment's consideration."

\section{FRACTURE AND CONCUSSION OF THE SPINE.}

TO THE EDITORS OF THE PROVINCIAL MEDICAL JOURNAL.

Gentlenen,-The following cases of fracture and concussion of the spine, although affording nothing of novelty, I send for insertion in your Journal; I conceive, with Mr. Toogood, that much substantial advantage results to the profession by the practice of faithfully publishing the cases which occur in our practice.

I have the honor to be, Gentlemen, Your obedient servant,

THomas Bancks, M.R.C.S.

Stourbridge, Aug. 8, 1843

C $_{\text {SSE }}$ I.-Richard Andrews, aged forty, whilst engaged in getting out coals in the mines, a quantity fell on his back, and fractured the last dorsal and first lumbar vertebræ. The usual attendant symptoms were present when I saw him, an hour after the accident-viz., loss of sense and motion below the scat of injury, loss of power in the sphincter ani, and retention of urine, priapism, \&c. Vomiting, with febrile symptoms soon set in, and subsided in the course of three weeks, and in a month his general health was pretty good, and he ate and drank well; still there was no symptom of returning sensibility or motion. 'This state of things went on for nine months, when hectic fever set in, and he gradually sunk. In this case nature seemed to have made a great effort, and I have thought it a good case for the application of the trephine, which I believe, had it been used when his health was good, would have been successful.

CASE II.-John Dudley, aged twenty-nine, a stout, plethoric subject, received his injury in the same way as the subject of the previous case, by a quantity of coals falling upon him whilst at work. His symptoms were paralysis of all the parts below the seat of injury, with tympanitic abdomen, vomiting, \&c. Hectic set in soon, and he died in seven weeks from the day of the accident. Had there been any interval warranting the application of the trephine, I should certainly have used it in this case; and I cannot account for the rapidity with which he sunk, compared with Andrews, the only difference being that of a vertebra in the seat of injury. It proves, when there is complete paralysis, the external contusions form no criterion as to the extent of injury the spinal chord has sustained.

CASE III.-John Geary, aged thirty-six. In this case the tumefaction was very great, and there was much difficulty in ascertaining what was really the extent of the injuries the spinal column had sustained; but my belief is, that, besides concussion of the spine, there was fracture of the arch of the first lumbar vertebra, as well as of the spinous process. The paralysis was as complete as in any of the former cases, with retention of urine, loss of power of the sphincter ani, \&c. I was much pleased, after three weeks' leeching, cupping, \&c., to find returning sensibility and motion, and, in five weeks, the power of the sphincter, and he was also able to pass his water. In nine months he was so far recovered as to resume his labor. This case I had pronounced hopeless; indeed, there was apparently less chance of recovery than in either of the others, for, independent of the complete paralysis, the external injuries seemed so much greater, and gave to me the idea of the injury to the spinal chord corresponding in severity.

During my pupilage I visited a man who had had fracture of the lumbar vertebræ four years previously. He had all the usual symptoms, and besides, the skin of the legs and thighs had put on a morbid action, being covered with large, coarse, horny-looking scales, some of them three inches in diameter, most loath. some to look at, and offensive to the smell, and desquamated once in five or six months. He lived seven years from the day of the injury.

\section{OBSERVATIONS AND RESEARCHES} UPON $A$ NEW SOLVENT

\section{FOR STONE IN THE BLADDER.}

By Alexander Ure, A.M.

In pursuing some inquiries relative to the treatment of certain forms of urinary disease, my attention was-directed to the properties of carbonate of lithia, a substance of which no therapeutic application has been heretofore made. It nevertheless occurs as a constituent of various mineral waters - namely, in 